\title{
The asymmetry between discoveries and inventions in the Nobel Prize in Physics
}

\section{Christoph Bartneck Eindhoven University of Technology}

Matthias Rauterberg Eindhoven University of Technology

\section{Abstract}

This paper presents an empirical study on the frequency of discoveries and inventions that were awarded with the. More than 70 per cent of all Nobel Prizes were given to discoveries. The majority of inventions were awarded at the beginning of the twentieth century and only three inventions had a direct application for society. The emphasis on discoveries moves the Nobel Prize further away from its original intention to reward the greatest contribution to society in the preceding year. We propose to strengthen the role of inventions for the Nobel Prize, which would encourage inventors to tackle important problems, such as global warming or the gap between the first and the third worlds.

\section{Keywords}

Nobel Prize in Physics inventions discoveries global warming social application

\section{Introduction}

Alfred Nobel mentioned in his testament that the interest of this fund 'shall be annually distributed in the form of prizes to those who, during the preceding year, shall have conferred the greatest benefit on mankind' (Nobel). More specifically, one part is given 'to the person who shall have made the most important discovery or invention within the field of physics'. Nobel did not further define the terms 'discovery' and 'invention', but the MeridianWebster Online Dictionary defines invention as 'a device, contrivance, or process originated after study and experiment' and discovery as 'to obtain sight or knowledge of for the first time'. It is likely that Nobel would have agreed to these generally accepted definitions.

The fundamental difference between an invention and a discovery is that the result of an invention is an artefact and the result of a discovery is a theory. Both require prior theories, a process of experimentation and both have a utilitarian function. A new microscope, for example, might allow a better measurement of a phenomenon and is therefore more useful than all previous microscopes. In the same way, a new theory that predicts a phenomenon better than previous versions is more useful. Discoveries also depend on inventions and vice versa. The times where one's own eyes were sufficient for relevant observation are long gone. Physics requires sophisticated machines, such as the particle accelerator at the European Organization for European Research CERN Laboratory or the Hubble Telescope in the orbitaround earth. Without these artefacts it would be extremely difficult to 
gain newinsights. But without a thorough understanding of magnetism and optics it would also be impossible to build these artefacts in the first place. Discoveries and inventions are mutually dependent.

It appears to us, however, that discoveries are much more respected by the scientific community than inventions. The Nobel Prize is the most esteemed scientific acknowledgement and its selection procedure depends heavily on the science community. Its social and political aspects have been discussed in detail (Friedman 2001). Various analyses are available that discuss the distribution of prizes across subfields, age and religion of the laureates, and the time interval between the actual work and its acknowledgement (Karazija and Momkauskait 2004; Zhang and Fuller 1998). The Nobel Prize offers a strong historical account of science and also systematic data (Shalev 2002). The Nobel Prizes form a solid and systematic data with which to answer our research question as to whether discoveries are more esteemed than inventions by the science community.

\section{Method}

We collected the short summaries of the Nobel Prize in Physics from the years 1901 to 2004 from the Nobel Foundation website. Even though certain prizes caused considerable debate and social and political issues cannot be excluded from the nomination procedure, it can be assumed that any of these biases would have affected discoveries and inventions equally.

The list of prizes was compiled into a questionnaire that asked the participant to classify each prize as either a discovery, an invention or both. In addition an 'I do not know' option was offered for every question. After reading the instructions and Nobel's testament, four academics were asked to fill in the questionnaire. A reliability analysis across the four judges resulted in a Cronbach's Alpha of .733, which gives us sufficient confidence in the opinions of the judges. The modus from the four classifications for each prize was taken. If, for example, three judges classified a certain prize to be a discovery and one classified it to be an invention, the prize would be considered a discovery. Two variables were used to reflect this transformation: ' $i$ ' for invention and ' $d$ ' for discovery. In our previous example, ' $i$ ' would receive a value of zero and ' $d$ ' would receive a value of one. These two variables are necessary, since the modus operation could also result in a prize to be both a discovery and an invention. In that case both ' $i$ ' and ' $d$ ' would receive a value of 0.5 . No instance occurred in which the modus operation resulted in an 'I do not know' classification. Furthermore we calculated the delay of each prize by subtracting the year of the actual work from the year in which the prize was given.

\section{Results}

We summarized the number of invention prizes and discovery prizes by decade and calculated the proportion of discoveries and inventions based on the values for ' $i$ ' and ' $d$ '. Figure 1 shows that there have always been more Nobel Prizes awarded to discoveries than to inventions. On average, 77 per cent of all Nobel Prizes in Physics were given to discoveries and 23 per cent to inventions.

It can also be observed that the delay between the origin of the work and its acknowledgment is increasing. Figure 2 shows that the delay has almost tripled over the last century. 


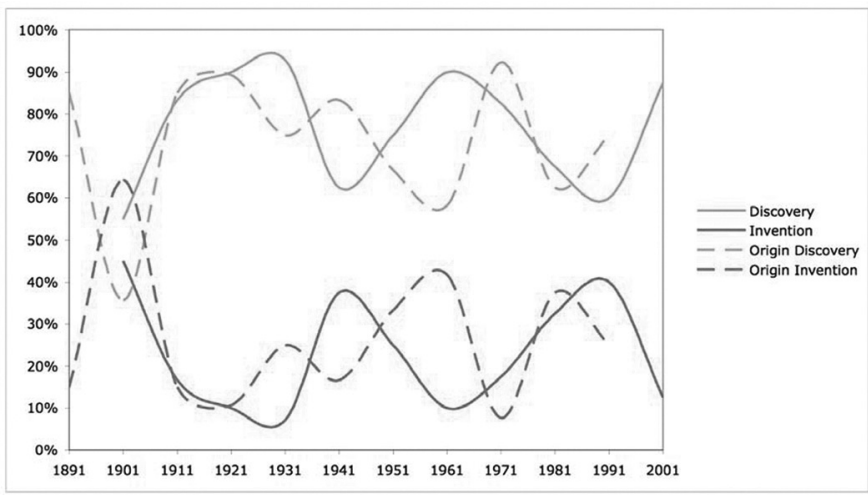

Figure 1: Proportion of Nobel Prizes in Physics given for discoveries and inventions per decade.

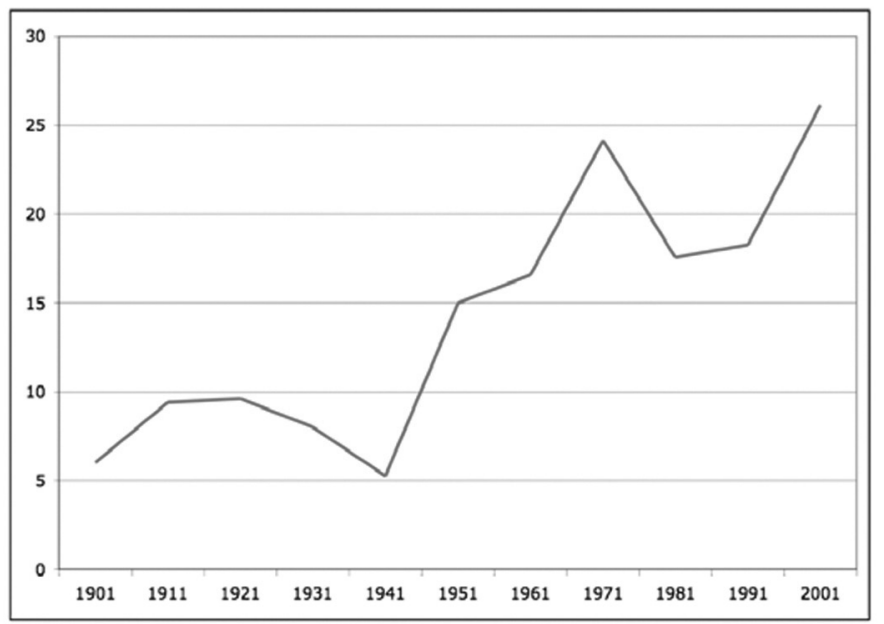

Figure 2: Delay in years between the origin of the work and its acknowledgement per decade.

To test this impression we conducted an analysis of covariance in which type (invention or discovery) was the fixed factor, year (year of the award) the covariant and the delay time the dependent measurement. While the type of prize had no significant influence on the delay $(F(2,111)=1.848$, $\mathrm{p}=.162)$, year did have a very significant influence $(\mathrm{F}(1,111)=32.2, \mathrm{p}<.001)$.

\section{Discussion}

Nobel did not specify in what proportion prizes should be awarded to inventions and discoveries. By preferring discoveries, the Nobel Foundation does not therefore violate Nobel's testament. Still, it is obvious that the academic community strongly favours discoveries. A closer look the awarded inventions reveals that eleven out of the total of seventeen inventions (64 per cent) can be considered measurement instruments. 
Nobel specified that the prize should be awarded to inventions within the field of physics. The majority of inventions that the field of physics awards are tools upon which their discoveries depend.

Other extremely beneficial inventions for mankind, such as the paper clip or the condom, did not receive the Nobel Prize and likely never will. This is mainly due to the fact that physics does not consider them to be part of its field. Even more technically sophisticated inventions, such as aeroplanes or mobile phones, did not receive the prize. Only three awarded inventions had direct practical applications: the gas regulator controlled buoys by Nils Gustaf Dalén were thereafter used in lighthouses, the transistor by Shockley, Bardeen and Brattain is widely used in electronic devices, and the integrated circuit by Jack Kilby made personal computers possible. It can also be observed that four out of six inventions were awarded at the beginning of the century between 1901 and 1912. It appears that the activity of inventing was split off into the field of engineering. At the same time we can confirm R. Karazija and A. Momkauskait's (2004) findings that the delay between the origin of the actual work and its award has significantly increased in the last century. In the last decade the average delay has amounted to 26 years. We could not find a significant difference between discoveries and inventions in the delay between the origin of the work and its resulting award. However, Nobel's testament clearly states that the prize money should be 'annually distributed in the form of prizes to those who, during the preceding year, shall have conferred the greatest benefit on mankind'. Since the statute of the Nobel Foundation does not allow the prize to be awarded posthumously, it will become increasingly difficult to choose suitable candidates if this delay-trend is continued. At some point, the committee will only be able to recommend dead scientists. The increase in the delay time together with the fact that barely any awarded inventions have a direct application, and therefore benefit, for society moves the Nobel Prize further away from its original intention to reward the greatest contribution to society. Refocusing the Nobel Prize on inventions might help to lead physics to results that are more easily transferable to direct benefits for society. The award given to Jack Kilby for the development of the integrated circuit is a good example. Modern computers certainly contributed to the field of physics, but they also had a great impact on society. The invention of the electric telephone, patented first by Graham Bell, can be considered a missed opportunity to acknowledge an important invention that brought the world closer together and helped to form a global consciousness, but there is still hope for Tim Berners-Lee's invention of the World Wide Web.

\section{References}

Friedman, R.M. (2001), The Politics of Excellence : Behind the Nobel Prize in Science, New York: Times Books.

Karazija, R. and Momkauskait, A. (2004), 'The Nobel Prize in Physics - Regularities and Tendencies', Scientometrics, 61(2), pp. 191-205.

Merra Webster Online Dictionary. http://www.merriam-webster.com/ [accessed 3.2.07].

Nobel, Alfred. (1895). Alfred Nobel's Will. http://nobelprize.org/alfred_nobel/will/ will-full.html

[accessed 3.2.07]. 
Nobel Foundation. http://nobelprize.org/nobelfoundation/index.html [accessed 3.2.07].

Shalev, B.A. (2002), 100 Years of Nobel Prizes, Los Angeles: Americas Group.

Zhang, W. and Fuller, R.G. (1998), 'Nobel Prize Winners in Physics from 1901 to 1990: Simple Statistics for Physics Teachers', Physics education, 33(3), pp. 196-203.

\section{Suggested citation}

Bartneck, C. and Rauterberg, M. (2008), 'The asymmetry between discoveries and inventions in the Nobel Prize in Physics', Technoetic Arts: A Journal of Speculative Research 6: 1, pp. 73-77, doi: 10.1386/tear.6.1.73/1

\section{Contributor details}

Christoph Bartneck is Assistant Professor in the Department of Industrial Design at the Eindhoven University of Technology. His background is in Industrial Design and Human-Computer Interaction and he has published and presented projects and studies in various journals and conferences. His interests lie in the area of Social Robotics, Design Science and Multimedia Applications. He has worked for several companies including the Technology Center of Hanover (Germany), LEGO (Denmark), Eagle River Interactive (USA), Philips Research (Netherlands) and ATR (Japan). Contact: Department of Industrial Design, Eindhoven University of Technology, Den Dolech 2, 5600MB Eindhoven, The Netherlands.

Email: c.bartneck@tue.nl

g.w.m.rauterberg@tue.nl

Matthias Rauterberg is the head of the Designed Intelligence research group at the Department of Industrial Design at the Eindhoven University of Technology. Since 1994 he has chaired a number of Technical Committees of the International Federation of Information Processing e.g. on Human Interaction, $\mathrm{HCl}$ and Education, Entertainment Computing and Entertainment Theory. He was Visiting Professor at Kwansei Gakuin University, Japan (2004-2007). He was awarded the Swiss Technology Award for the BUILD-IT system in 1998, and has over 250 publications in international journals, conference proceedings, and books. He is on the editorial board of several leading international journals. Contact: Department of Industrial Design, Eindhoven University of Technology, Den Dolech 2, 5600MB Eindhoven, The Netherlands.

Email: c.bartneck@tue.nl g.w.m.rauterberg@tue.nl 